13 - ORIGINAL ARTICLE

ALIMENTARY TRACT

\title{
Effects of ischemic preconditioning associated to different preservation solutions in protecting the intestinal graft ${ }^{1}$
}

\author{
Efeitos do precondicionamento isquêmico associado a diferentes soluções de preservação na \\ proteção do enxerto intestinal
}

\begin{abstract}
José de Souza Neves', Marcos de Souza Abrahão"I, Alcides Augusto Salzedas Netto ${ }^{\text {III }}$, Edna Frasson de Souza Montero ${ }^{\text {IV }}$, Adriano Miziara Gonzalez ${ }^{\mathrm{V}}$

${ }^{\mathrm{I}} \mathrm{PhD}$, Assistant Professor, Department of Surgery, University of Mato Grosso, Brazil. Conception, responsible for design, intellectual and scientific content of the article, and manuscript writing.

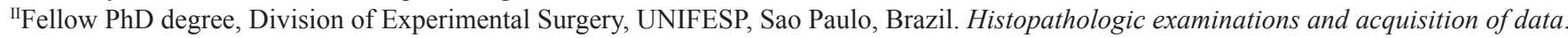

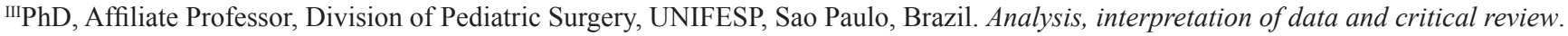

${ }^{\text {IV }} \mathrm{PhD}$, Affiliate Professor, Division of Experimental Surgery, UNIFESP, Sao Paulo, Brazil. Experimental design, analysis, interpretation of data and critical review.

vPhD, Associate Professor, Transplant Division, Department of Surgery, UNIFESP, Sao Paulo, Brazil. Analysis, interpretation of data and critical review.
\end{abstract}

\section{ABSTRACT}

PURPOSE: To evaluate the effects of ischemic preconditioning (IPC) associate with different preservation solutions, in the protecting of gut.

METHODS: Four groups of 14 rats underwent laparotomy and collecting $20 \mathrm{~cm}$ of ileum, for preservation, at $4^{0} \mathrm{C}$, in $\mathrm{Belzer}(\mathrm{Belz})$, Ringer (RL), Celsior (Cs) and Custodiol (Cust) solutions, for 24 hours. Prior to collection, half of the animals in each group were subjected to IPC. During preservation, in the periods of zero, 12, 18 and 24 hours, were conducted evaluating the degree of mucosal injury and dosage of malondialdehyde acid (MDA).

RESULTS: In all periods the RL group, with and without IPC, presented MDA values higher than the Belz and Cs. The degree of mucosal injury in the non-ipc RLgroup with $12 \mathrm{~h}$ preservation was higher than the others; with 18 and $24 \mathrm{~h}$, the RL and Cust had higher degrees of damage than Cs and Belz. With IPC, in all periods, the group Cs and Belz had lower degrees of injury.

CONCLUSION: The Celsior and Belzer solutions had better protective effects on the gut and these effects were enhanced by IPC. Keywords: Organ Preservation Solutions. Ischemic Preconditioning. Intestine, Small. Rats.

\section{RESUMO}

OBJETIVO: Avaliar os efeitos do precondicionamento isquêmico (PCI) associado a diferentes soluções de preservação, na proteção do intestino delgado.

MÉTODOS: Quatro grupos de 14 ratos Wistar, foram submetidos à laparotomia e coleta de $20 \mathrm{~cm}$ de íleo, para preservação, a $4^{0} \mathrm{C}$, nas soluções de Belzer (Belz), Ringer (RL), Celsior (Cs) e Custodiol (Cust) por 24 horas. Previamente à coleta, em metade dos animais de cada grupo, o intestino foi submetido ao PCI. Durante a preservação, nos períodos de Zero, 12, 18 e 24 horas, foram realizados avaliação do grau de lesão da mucosa e dosagem do ácido malondialdeído (MDA).

RESULTADOS: Em todos os períodos o grupo RL, sem e com pci, apresentou valores maiores de MDA do que o Belz e Cs. O grau de lesão da mucosa nos grupos sem pci com preservação de $12 \mathrm{~h}$, no grupo RL, foi maior que nos demais; com 18h e 24h o grupo RL e Cust apresentaram maiores graus de lesão do que Cs e Belz. Com o pci, em todos os períodos, os grupos Belz e Cs apresentaram menores graus de lesão

CONCLUSÃO: As Soluções Celsior e Belzer tiveram melhores efeitos na proteção do intestino e estes efeitos foram incrementados pelo precondicionamento isquêmico.

Descritores: Soluções para Preservação de Órgãos. Precondicionamento Isquêmico. Intestino Delgado. Ratos. 


\section{Introduction}

The small bowel transplantation (SBT) is the proposed treatment for various intestinal disorders. However, in despite of significant advances, the bowel graft preservation is still a challenge. The SBT is indicated especially for patients who underwent extensive small bowel resection and evolved with short bowel syndrome and intestinal failure. In such cases the patient usually becomes dependent of parenteral nutrition (TPN) for survival. The maintenance of patients with venous nutrition therapy, for long times, presents a number of complications and the alternative, in some cases, is the transplantation ${ }^{1,2}$.

Currently the SBT is technically well established but the results are still lower than the other organs and the morbidity and mortality remain high. The complications in most patients, are related to the occurrence of primary graft dysfunction, induced by injuries during the period of cold ischemic preservation, reperfusion injury, rejection and infection. Advances in immunosuppressive therapy, like the use of tacrolimus, have provided improvements in rates of rejection and infection, resulting in a decrease in mortality rates, which nevertheless still remain around to $50 \%$ at 5 years post-transplant ${ }^{1,3}$.

Preservation injury is caused primarily by ischemia and hypothermia. The small intestine is the most perfused organ, receiving around $25 \%$ of blood pumped by the heart and of that amount $90 \%$ are consumed in the mucosa and submucosa, which are the areas earlier affected by ischemia. The interruption of oxygen supply to tissues leads to inhibition of mitochondrial oxidative phosphorylation and a fall in production and supply of adenosine triphosphate. Hypothermia, which is indispensable to the preservation is another factor that, paradoxically, provides breakdown in cell physiology. The main side effects of hypothermia are cellular swelling, acidosis, and generation of free radicals such as hydrogen peroxide $\left(\mathrm{H}_{2} \mathrm{O}_{2}\right)$, superoxide anion $\left(\mathrm{O}_{2}-\right)$ and hydroxyl radical $(-\mathrm{OH})^{2,4}$

Fundamentally the proper preservation depends on actions against the deleterious effects of ischemia and hypothermia. The first preservation solution formulated were Collins and Eurocollins, developed for use in preserving renal hypothermic. In the early 70's, a new solution, the Custodiol, also known as HTK (histidine-tryptophan-ketoglutarate), initially indicated to cardioplegia in heart surgery, began to be tested also in the preservation of kidneys and digestive organs ${ }^{4}$. In 80's, discovery of immunosuppressants became possible to perform transplants of liver, pancreas and intestine and at that time, a new solution was developed in the University of Wisconsin (Belzer's Solution), for the preservation of the liver. In the last years various solutions have been introduced, as Celsior, IGL-1 (developed at the Institute George Lopez - Lyon / France) and Polysol, among others ${ }^{4,5}$.

In general, the solutions are formulated to reduce the harmful effects of hypothermia and provide energetic substrate. Thus, the solutions contain, for example, impermeants like histidine and lactobionate, buffer as $\mathrm{KH}_{2} \mathrm{PO}_{4}$, and antioxidants such as glutathione, which act by eliminating free radicals ${ }^{4,5}$

Specifically in relation to the small intestine, there are a variety of clinical and experimental studies, comparing the protective effects of different preservation solutions ${ }^{6}$. The results are quite different and in reality, to date, a preservation solution specific to gut protection, was not yet developed. The small bowel is difficult to be preserved and the maximum time of preservation, with current methods, according to some authors, is around 10 hours ${ }^{2}$.

A perspective came when some authors observed experimentally that the myocardium of dogs, previously submitted to short cycles of ischemia and reperfusion, became more resistant to the prolonged ischemia, including reduction of necrotic area ${ }^{7}$. This protection mechanism was known as ischemic preconditioning (IPC), leading some researchers to study the phenomenon in other organs such as lung, liver and intestine $e^{2,7,8}$. The results of these studies generally showed that the IPC confers some protection to the organs evaluated, with reduction of injuries due to ischemia and reperfusion.

The mechanisms by which the IPC acts remain not clear, however, its effects may be mediated by endogenous production of nitric oxide (NO). IPC possibly acts by reducing the conversion of ATP to hypoxanthine, decreasing the ability of free radical production and stimulating the production of antioxidants ${ }^{8,9}$.

There is no consensus as to which solution is best suited to preserve the intestine; there is neither experimental studies evaluating the effects of IPC in association with different preservation solutions.

The aim of this study was assess the effects of ischemic preconditioning associated with Celsior, Custodiol, Belzer and Ringer-Lactate solutions in the protection of the small bowel during hypothermic ischemic preservation phase and assess which of the preservation solutions, alone, is more effective in protecting the gut during hypothermic preservation.

\section{Methods}

This research was approved by the Ethics Committee of the Federal University of Sâo Paulo (UNIFESP) with Reference CEP No $1278 / 08$. 


\section{Experimental design}

It was used 56 rats and 4 types of preservation solutions. The animals were randomly assigned to 4 groups of 14 animals each, according to the type of solution: Groups Ringer lactate, Celsior, Custodiol and Belzer. Half the animals in each group underwent IPC forming a subgroup with and another without preconditioning.

The Celsior and Belzer solutions contain the antioxidant glutathione and Custodiol, also named HTK, is mainly composed by histidine, tryptophan and ketoglutarate. The full composition of the solutions is shown by Weil et al. ${ }^{5}$.

All rats were anesthetized intramuscularly with a solution of ketamine $(90 \mathrm{mg} / \mathrm{kg})$ and xylazine $(20 \mathrm{mg} / \mathrm{kg})$, laparotomy and collection of ileal segment for preservation for 24 hours, in the solution corresponding to the group. During the period of preservation, intestinal samples were collected for analysis and evaluation of which solutions, in combination with IPC, obtained better performance in intestinal preservation. The parameters analyzed were score of the degree of mucosal injury according to scheme proposed by Park et al. ${ }^{10}$ and quantification of malondialdehyde acid (MDA) by the thiobarbituric acid test $(\text { TBARS })^{11}$.

It were used Wistar rats, adult, male, weighting between 250 and $300 \mathrm{~g}$, coming from the Central Animal Laboratory, Faculty of Medicine, Federal University of Mato Grosso. In the period before the experiment, the animals were kept in individual cages, fed with a proper diet for the species (Purina ${ }^{\circledR}$ ) and free access to water. The temperature and the cycles of light and dark in the laboratory environment were controlled, so that the conditions remain suitable for the animals in the experiment.

\section{Surgical procedure}

The surgery consisted of midline incision, opening the peritoneum, exposing of the bowel, opening the retroperitoneum, isolation of the aorta and superior mesenteric artery (SMA). In the subgroups without IPC, after 20 minutes of observation, the aorta was cannulated just below the SMA and it was infused $40 \mathrm{ml}$ of the respective preservation solution, corresponding to the group. In animals of subgroups with IPC, it was performed the occlusion of the SMA, with bulldog clamp type, for 10 minutes followed by reperfusion for the same period. At the end of the period established for the IPC, the aorta was cannulated and the solution perfused. Immediately at the start of perfusion, right thoracotomy was performed, section of the inferior vena cava and drainage the solution infused into the mesenteric arcade. The euthanasia was performed by exsanguination.

\section{Collection of intestinal segments for preservation}

At the final period of vascular perfusion, it was collected $20 \mathrm{~cm}$ of ileal segment, measured from $2 \mathrm{~cm}$ of the ileocaecal valve. One sample of $5 \mathrm{~cm}$ was immediately separated for histological analysis (zero hour sample) and MDA dosage. The rest, $15 \mathrm{~cm}$, was placed in a vial containing $50 \mathrm{ml}$ of preservation solution referring to the group and preserved for 24 hours at $4^{\circ} \mathrm{C}$. Intestinal samples were collected when completing the periods of 12,18 and 24 hours of preservation to morphological and biochemical (measurement of MDA) analysis.

\section{Measurement of MDA}

Samples collected were submerged in liquid nitrogen for freezing and sent to determination of MDA content that was performed by thiobarbituric acid test (TBARS) ${ }^{11}$. This test is based on the reaction of MDA with thiobarbituric acid at low $\mathrm{pH}$ and high temperature, forming the MDA-TBA complex, with its own color and absorption, which can be detected by spectrophotometer. The samples, still frozen, were macerated in an ice bath and suspended in a saline solution from which was taken $100 \mathrm{ul}$, added to sodium sulfate solution, $2.5 \mathrm{ml}$ of TBA, and reagent buffer (acetic acid, thiobarbituric acid and sodium hydroxide). The tubes were covered and incubated at $95^{\circ} \mathrm{C}$ for 1 hour, cooled, and centrifuged for 15 minutes at $3000 \mathrm{rpm}$. The supernatant was removed, prepared and analyzed in a spectrophotometer with a wavelength of $532 \mathrm{~nm}$.

\section{Morphological analysis}

To assessment of mucosal injury, samples of $2 \mathrm{~cm}$ were collected, placed in formaldehyde at $10 \%$ and sent to Laboratory for preparation of the paraffin blocks. After paraffin embedding, ileum fragments were sectioned to $4 \mu \mathrm{m}$-thick microtome, attached on slides and stained by hematoxylin-eosin (H.E). The analysis of injury degrees were performed under a light microscope by pathologist blinded to the project data. The degree of mucosal injury was classified according to the criteria proposed by Park et al. ${ }^{10}$.

\section{Statistical analysis}

For data analysis, it was used the statistical software SPSS version 15.0 for Windows. The $\mathrm{p}<0.05$ or $5 \%$ was considered statistically significant. The descriptive analysis of continuous 
variable was described by mean and standard deviation. For the inferential analyze of mucosal injury degree were applied the nonparametric Kruskal-Wallis test to verify the hypothesis of equality between the four groups and Mann-Whitney, to check the equality of groups 2 to 2 , when difference was detected. To analyze of MDA were applied the analysis of variance (One-way ANOVA) and Tukey test, to check the equality of groups 2 to 2 , when difference was detected.

\section{Results}

In the evaluation of MDA was observed that those subgroups without IPC and preserved with Ringer-Lactate showed higher values of MDA denoting greater degree of lipid peroxidation of cell membranes. The other groups showed similar results. In groups with IPC, within $12 \mathrm{~h}$ of preservation, the ileum preserved with Custodiol had significantly higher values of MDA and thus more cell membrane injury than those preserved with Belzer solution. After $18 \mathrm{~h}$ of preservation, there is progressive decrease of MDA in all groups (Table 1, Figures 1 and 2).

TABLE 1 - Mean and standard deviation of MDA value, in nmol/mg tissue, groups Ringer, Celsior, Custodiol and Belzer, without and with ischemic preconditioning, at zero, 12, 18 and 24 hours of preservation.

\begin{tabular}{ccccccc}
\hline & & Ringer & Celsior & Custodiol & Belzer & $p$ \\
\hline \multirow{2}{*}{ Zero } & without & $2.40 \pm 0.5$ & $1.52 \pm 0.9$ & $2.30 \pm 0.4$ & $1.57 \pm 0.8$ & 0.104 \\
\cline { 2 - 7 } & with & $2.87 \pm 1.0$ & $1.50 \pm 0.8$ & $2.80 \pm 1.2$ & $1.50 \pm 0.6$ & 0.015 \\
\hline \multirow{2}{*}{$\mathbf{1 2}$} & without & $3.56 \pm 1.1$ & $2.33 \pm 1.6$ & $2.90 \pm 1.1$ & $1.70 \pm 0.7$ & 0.053 \\
\cline { 2 - 7 } & with & $3.10 \pm 0.8$ & $1.92 \pm 0.8$ & $2.80 \pm 0.6$ & $1.60 \pm 0.5$ & 0.002 \\
\hline \multirow{2}{*}{$\mathbf{1 8}$} & without & $4.40 \pm 1.6$ & $3.50 \pm 1.4$ & $2.37 \pm 0.6$ & $2.70 \pm 0.9$ & 0.030 \\
\cline { 2 - 7 } & with & $4.30 \pm 1.4$ & $3.10 \pm 0.8$ & $3.03 \pm 0.5$ & $2.30 \pm 0.7$ & 0.007 \\
\hline \multirow{2}{*}{$\mathbf{2 4}$} & without & $4.21 \pm 1.0$ & $3.26 \pm 1.4$ & $2.0 \pm 1.0$ & $2.52 \pm 0.6$ & 0.005 \\
\cline { 2 - 6 } & with & $3.90 \pm 1.5$ & $2.20 \pm 0.7$ & $2.0 \pm 0.7$ & $1.47 \pm 0.8$ & 0.001 \\
\hline
\end{tabular}

Statistical calculation comparing the four groups without and with IPC: ANOVA

$\mathrm{NS}=$ without significance $; *=$ statistically significant

Tukey test: groups without IPC:

\section{Zero NS ; 12h: NS}

$18 \mathrm{~h}$

$\mathrm{RL}=\mathrm{Cs}(\mathrm{p}=0,542) ; * \mathrm{RL}>\operatorname{Cust}(\mathrm{p}=0,028) ;$ $\mathrm{RL}=\operatorname{Belz}(\mathrm{p}=0,102) ; \mathrm{Cs}=\mathrm{Cust}(\mathrm{p}=0,358) ; \mathrm{Cs}$ $=\operatorname{Belz}(\mathrm{p}=0,715) ;$ Cust $=\operatorname{Belz}(\mathrm{p}=0,927)$.

$$
\begin{aligned}
& \mathrm{RL}=\mathrm{Cs}(\mathrm{p}=0,376) ;{ }^{\mathrm{RL}}>\text { Cust } \\
& (\mathrm{p}=0,005) ; * \mathrm{RL}>\operatorname{Belz}(\mathrm{p}=0,035) ; \mathrm{Cs}=\mathrm{Cust} \\
& (\mathrm{p}=0,168) ; \mathrm{Cs}=\mathrm{Belz}(\mathrm{p}=0,582) ; \text { Cust }=\text { Belz } \\
& (\mathrm{p}=0,825) .
\end{aligned}
$$

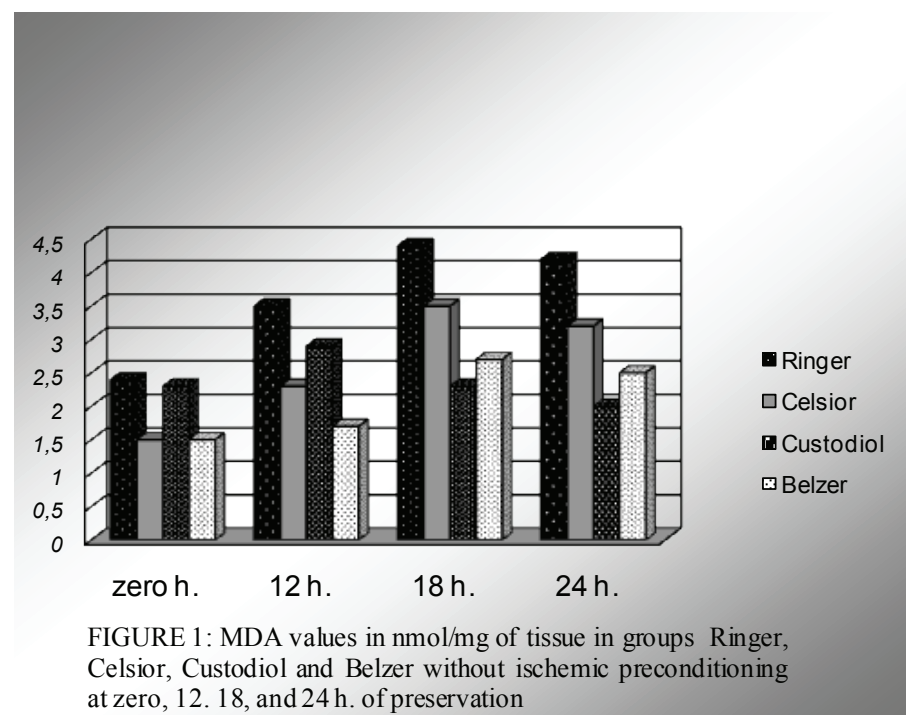

Zero: NS

Tukey test: group with IPC

$* \mathrm{RL}>\mathrm{Cs}(\mathrm{p}=0,016) ; \mathrm{RL}=\operatorname{Cust}(\mathrm{p}=0,784) ; * \mathrm{RL}>\operatorname{Belz}$

$12 \mathrm{~h} \quad(\mathrm{p}=0,003) ; \mathrm{Cs}=\operatorname{Cust}(\mathrm{p}=0,121) ; \mathrm{Cs}=\operatorname{Belz}(\mathrm{p}=0,904)$;

${ }^{*}$ Cust $>$ Belz $(\mathrm{p}=0,029)$.

$\mathrm{RL}=\mathrm{Cs}(\mathrm{p}=0,129) ; \mathrm{RL}=$ Cust $(\mathrm{p}=0,086) ;$

$18 \mathrm{~h} \quad * \mathrm{RL}>\operatorname{Belz}(\mathrm{p}=0,004) ; \mathrm{Cs}=\mathrm{Cust}(\mathrm{p}=0,997)$;

$\mathrm{Cs}=\operatorname{Belz}(\mathrm{p}=0,407) ; \operatorname{Cust}=\operatorname{Belz}(\mathrm{p}=0,529)$.

$* \mathrm{RL}>\mathrm{Cs}(\mathrm{p}=0,020) ;{ }^{*} \mathrm{RL}>\mathrm{Cust}$

$24 \mathrm{~h} \quad(\mathrm{p}=0,012) ;{ }^{*} \mathrm{RL}>\operatorname{Belz}(\mathrm{p}=0,001) ; \mathrm{Cs}=$ Cust $(\mathrm{p}=0,996)$;

$\mathrm{Cs}=\operatorname{Belz}(\mathrm{p}=0,524) ; \mathrm{Cust}=\operatorname{Belz}(\mathrm{p}=0,658)$. 


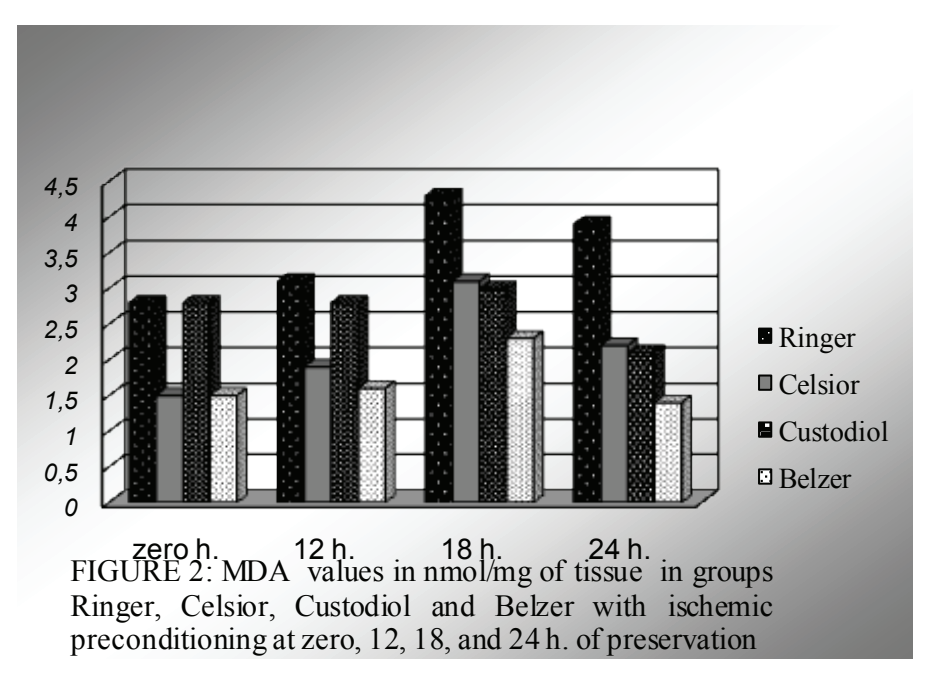

Degree of mucosal injury

The results regarding the grades of mucosal injury showed progression of lesions over time and decrease with the achievement of IPC. The Ringer group, at all times, presents greater degree of mucosal injury. With 12, 18 and 24 hours of preservation, the Custodiol group showed higher levels of damage than the groups Celsior and Belzer and these results became even more evident and more significant with the implementation of IPC (Table 2, Figures 3 and 4).

TABLE 2 - Mean, standard deviation and median of the degree of mucosal injury with Zero, 12, 18 and 24 hours of preservation, groups Ringer, Celsior, Custodiol and Belzer, without and with ischemic preconditioning.

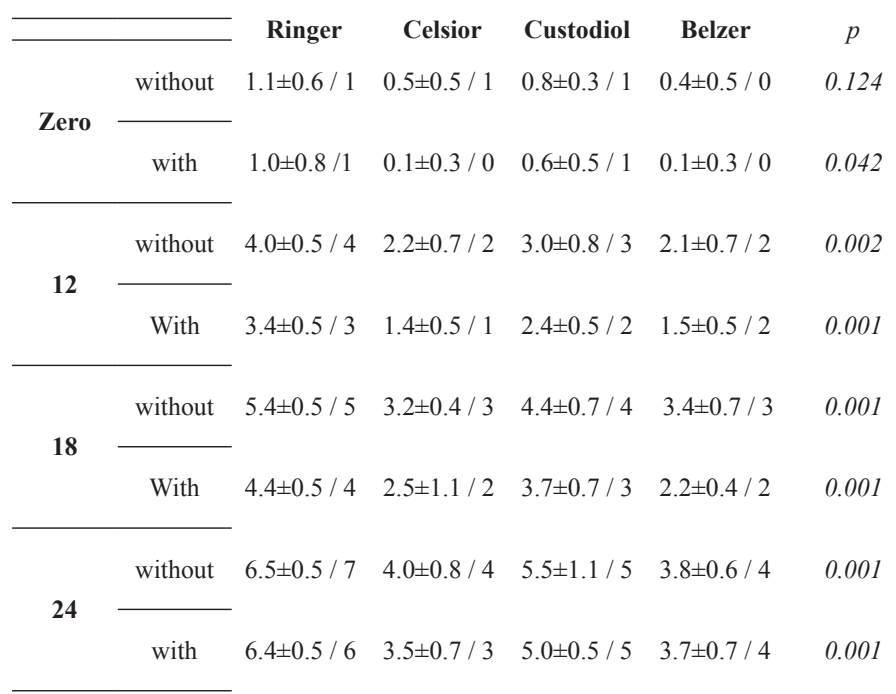

statistical test: kruskal-Wallis; NS=without significance $; *=$ statistically significant
Mann-Whitney test: group without IPC

Zero

\section{NS}

$12 \mathrm{~h}$

$$
\begin{aligned}
& * R L>C s(p=0,002) ; * R L>C \text { Cust }(p=0,027) ;{ }^{*} \mathrm{RL}>\operatorname{Bel} \\
& z(p=0,002) ; C s=\text { Cust } \\
& (p=0,133) ; \quad \text { Cs }=\text { Belz }(p=0,674) ; \quad \text { Cust }=\text { Belz } \\
& (p=0,065) .
\end{aligned}
$$

*RL $>\operatorname{Cs}(p=0,001) ; * R L>\operatorname{Cust}(p=0,09) ; *$

18h $\quad \mathrm{RL}>\operatorname{Belz}(\mathrm{p}=0,002) ;{ }^{*} \mathrm{Cust}>\mathrm{Cs}(\mathrm{p}=0,014)$; $\mathrm{Cs}=\operatorname{Belz}(\mathrm{p}=0,087) ;{ }^{*} \operatorname{Cust}>\operatorname{Belz}(\mathrm{p}=0,040)$.

$* \mathrm{RL}>\mathrm{Cs}(\mathrm{p}=0,001) ; \mathrm{RL}=$ Cust

$24 \mathrm{~h}$ $(\mathrm{p}=0,079) ;{ }^{*} \mathrm{RL}>\operatorname{Belz}(\mathrm{p}=0,001) ;{ }^{*}$ Cust $>\mathrm{Cs}$ $(\mathrm{p}=0,017) ; \mathrm{Cs}=\operatorname{Bel} \mathrm{z}(\mathrm{p}=0,728) ;{ }^{*} \mathrm{Cust}>\operatorname{Belz}$ $(\mathrm{p}=0,008)$.

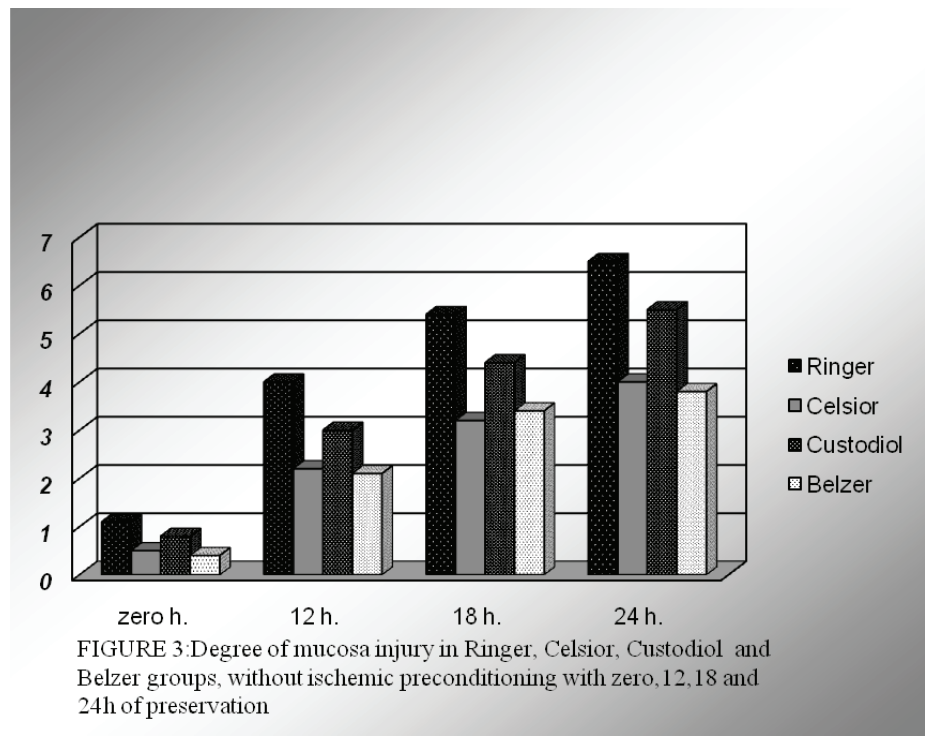


Mann-Whitney test: group without IPC

$$
\begin{aligned}
& * \mathrm{RL}>\mathrm{Cs}(\mathrm{p}=0,031) ; \mathrm{RL}=\mathrm{Cust}(\mathrm{p}=0,293) ;{ }^{*} \mathrm{RL}>\operatorname{Belz}( \\
& \text { Zero } \mathrm{p}=0,031) \text {; } \mathrm{Cs}=\mathrm{Cust} \\
& (p=0,107) ; \operatorname{Cs}=\operatorname{Belz}(p=1,000) ; \operatorname{Cust}=\operatorname{Belz}(p=0,107) \text {. }
\end{aligned}
$$

$$
\begin{aligned}
& * \mathrm{RL}>\mathrm{Cs}(\mathrm{p}=0,011) ; \quad \mathrm{RL}=\text { Cust } \quad(\mathrm{p}=0,071) \text {; } \\
& 18 \mathrm{~h} * \mathrm{RL}>\operatorname{Belz}(\mathrm{p}=0,001) \text {; } \\
& { }^{*} \operatorname{Cust}>\operatorname{Cs}(\mathrm{p}=0,028) ; \quad \mathrm{Cs}=\operatorname{Belz}(\mathrm{p}=0,872) \text {; } \\
& * \text { Cust }>\operatorname{Belz}(\mathrm{p}=0,0040) \text {. }
\end{aligned}
$$

$* \mathrm{RL}>\mathrm{Cs}(\mathrm{p}=0,001) ;{ }^{*} \mathrm{RL}=\mathrm{Cust}(\mathrm{p}=0,002) ;{ }^{*} \mathrm{RL}>\mathrm{Bel} \mathrm{z}$ $24 \mathrm{~h} \quad(\mathrm{p}=0,001) ;{ }^{*} \mathrm{Cust}>\mathrm{Cs}(\mathrm{p}=0,007) ; \mathrm{Cs}=\operatorname{Belz}(\mathrm{p}=0,674)$; Cust $>\operatorname{Belz}(\mathrm{p}=0,008)$.

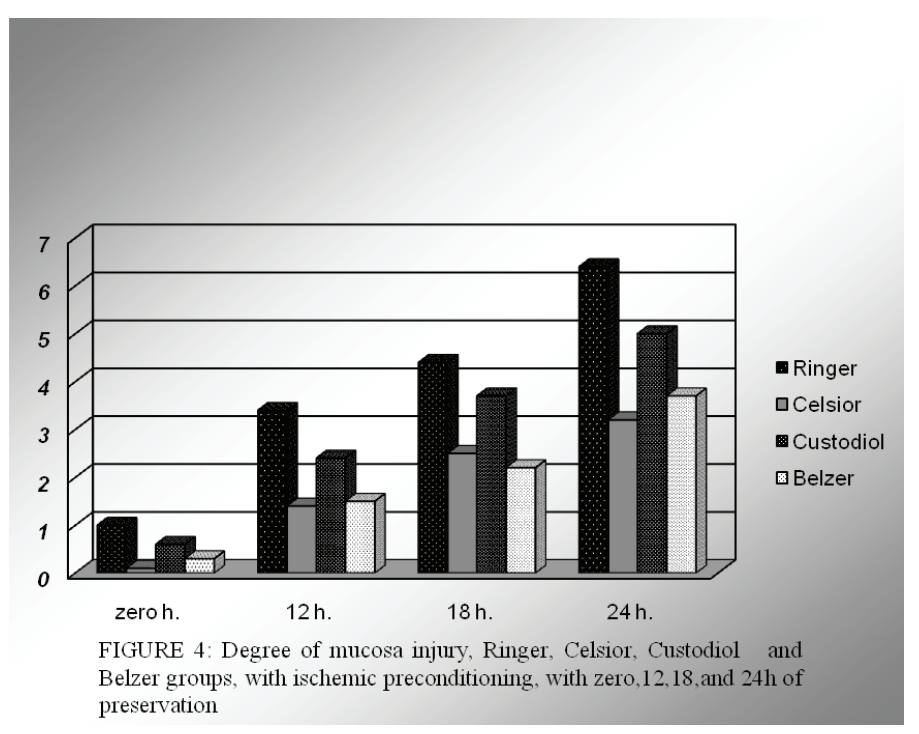

\section{Discussion}

The morphological integrity of the transplanted small bowel is essential for the full success of the transplant. The proper preservation of the intestinal graft is essential to prevent complications, such as bacterial translocation and sepsis, the leading cause of mortality after transplantation, accounting for approximately 60 to $70 \%$ of deaths. The hypothermic preservation of the small intestine was one of the first techniques used to maintain the viability of the graft. It seeks to extend the period of preservation infusing and immersing the graft in the cold preservation solution ${ }^{2,4}$.

These liquid solutions emerged as a mechanism to minimize the side effects of hypothermia. The Belzer's solution, formulated at the University of Wisconsin (UW) in late 1980 is still considered, according Oltean et al. ${ }^{2}$, as the gold standard for abdominal organ preservation. The UW solution has a high concentration of potassium (130mmol/l), containing also: lactobionic acid and raffinose, impermeant of high molecular weight that prevent intracellular edema; hydroxy-ethyl-starch (HES), which gives oncotic activity; and glutathione, antioxidant introduced to attenuate oxidative stress. The Custodiol, a preservation solution alternative, has a buffer system composed of histidine/histidine chloride and impermeant (ketoglutarate), but in electrolyte content is similar to the extracellular medium unlike Belzer's solution. There is growing evidence suggesting that Custodiol has good results in the preservation of liver and pancreas, but the results for intestinal preservation still need further studies to be proved ${ }^{4,5}$. Celsior is another solution that has been tested in intestinal preservation. Its formulation appears as a hybrid of the previous two, containing reduced glutathione; mannitol and lactobionic acid; high sodium concentration (100 $\mathrm{mmol} / \mathrm{l}$ ) with low potassium, similar to UW; and histidine, that also composes the Custodiol $^{6}$.

It has been postulated that an ideal preservation solution should preserve the structure of the intestinal epithelium during the cold ischemic storage. Regarding the effects of preservation solutions there are several studies and results are quite controversial ${ }^{5}$. Straatsburg et al. ${ }^{6}$ evaluated apoptosis and necrosis in rat liver after hypothermic preservation, concluded that Celsior and UW were more effective than HTK. Wei et al..$^{5}$ investigated the effects of a new solution, Polysol, in intestinal preservation and concluded that this solution was superior to Custodiol and Celsior, which was considered superior to UW. Mangus et al. ${ }^{12}$, in a clinical study, which compared Custodiol and Belzer in intestinal and multivisceral transplant, assessed the survival rate of graft and patients, observing no differences between solutions.

In addition to hypothermia and liquid solutions, it has been investigated other methods to improve preservation as the ischemic preconditioning (IPC), which involves subjecting the graft to short cycles of ischemia and reperfusion before the harvest ${ }^{7}$. Many experimental studies in rats have shown that IPC reduces the intensity of the ischemic lesions ${ }^{8,13}$. Clinically, in hepatic surgery, some authors as Clavien et al..$^{14}$ observed lower enzyme changes and less endothelial apoptosis of liver cells in patients submitted to the IPC, when compared to the group not 
subject to the procedure. The mechanisms by which the IPC acts, still not fully understood. A greater maintenance in energy cellular occurs with IPC by decreasing of the conversion of ATP to hypoxanthine and thereafter, by decreasing production of oxygen free radicals (OFR). Moreover there is an increased production of antioxidant and nitric oxide (NO), which seems to be a key facilitator of the process ${ }^{9}$. The present study speculated that the IPC in combination with the various preservation solutions would present different results. The methods employed to assess the intestinal preservation were analyze of mucosal damage and MDA content in intestinal tissue. The molecule of MDA results of cell membrane destruction by OFR, which occurs in tissues under oxidative stress. This process, known like lipid peroxidation, resulting in a chain reaction mediated by OFR with the oxidative deterioration of polyunsaturated fatty acids, the major components of the lipid bilayer, comprising the cell membrane.

The results of MDA values in the non-PCI groups, with zero hours of preservation, showed no statistically significant difference. With 12, 18 and 24 h., in the Ringer group, the MDA content were significantly higher than others. This indicates that lipid peroxidation was more intense in these groups. Ringer lactate actually has not composition suitable for tissue preservation and possibly the effects observed in this group are due solely to hypothermia. It should be noted also that the Celsior and Belzer solutions contain the antioxidant glutathione and it possibly should have reduced the peroxidation of the cell membrane in these groups. To making the IPC, was observed a decrease in the MDA in all groups. This study, however, did not perform the comparison between groups with and without IPC, because this comparison is beyond the scope of this research, besides the influence of IPC in ischemia/reperfusion and ischemia itself is well established in the literature.

The analyze of mucosal injury is considered a gold standard method when it wants to examine the effectiveness of preservation methods and is the most commonly used parameter to assess the quality of the intestinal graft under cold storage.

Balaz et al. ${ }^{8}$, comparing the effects UW and Custodiol solutions in intestinal hypothermic preservation, assessing the degree of injury and the concentration of serotonin in the mucosa concluded that the UW solution had better effect protector. Tesi et $a l .{ }^{15}$, in a clinical study evaluated the histological changes in the small intestine preserved in viaspan solution ${ }^{\circledR}(\mathrm{UW})$ concluded that the morphology maintains near normal by $6 \mathrm{~h}$ and that after $9 \mathrm{~h}$ of ischemia, severe mucosal injury occurs with total detachment of the epithelial layer.

In the present research, analysis of the degree of mucosal injury in the samples with zero hour of preservation in the nonIPC groups, showed no statistically significant differences, but on performing the IPC, the Celsior, Belzer and Custodiol group had lower injuries than the Ringer. With $12 \mathrm{~h}$ of preservation in the intestines without IPC, all groups, except Ringer, had equal severity of damage, but when performing IPC, Celsior and Belzer groups began to show lower scores of injuries than the Ringer and Custodiol. With $18 \mathrm{~h}$ of preservation in the groups without IPC, Celsior and Belzer had also similar results, with less pronounced lesions than another. With the IPC, the Ringer group showed the same lesion score of Custodiol, and both higher than the Celsior and Belzer. Completed 24h, the severity of injuries continued progress; however, the groups maintained the same pattern and the same proportionality in intensity of injuries. When performed IPC, there was overall reduction of injuries and Custodiol group also began to show a lower degree of injury than the Ringer. According to experimental model and methodology proposed in this research and considering the results obtained, the solution Celsior and Belzer associated with the IPC showed similar results and better than Ringer lactate and Custodiol.

Concerning the IPC, whose beneficial effects on preservation of liver, intestine, and other organs, are widely supported in the literature, there is agreement with the results of this study. The IPC increased positively the effects of preservation solutions, and therefore can be considered as an important adjunct in improving the quality of intestinal preservation. The clinical application of this technique can be evaluated when the intestinal transplants are more widely spread ${ }^{3}$, enabling the use of new techniques such as this widely based on experimental studies.

\section{Conclusion}

The intestinal ischemic preconditioning associated with Belzer and Celsior solutions were more effective in protecting the intestine from the oxidative stress and mucosal injury.

\section{References}

1. Fishbein TM. Intestinal transplantation. $\mathrm{N}$ Engl $\mathrm{J}$ Med. 2009;361(10):998-1008.

2. Oltean M, Joshi M, Herlenius G, Olausson M. Improved intestinal preservation using an intraluminal macromolecular solution: evidence from a rat model. Transplantation. 2010;89:285-90.

3. Fryer JP. The current status of intestinal transplantation. Curr Opin Organ Transplant. 2008;13:266-72.

4. Maathuis MH, Leuvenink HG, Ploeg RJ. Perspectives in organ preservation. Transplantation. 2007;83(10):1289-98.

5. Wei L, Hata K, Doorschodt BM, Büttner R, Minor T, Tolba RH. Experimental small bowel preservation using Polysol: a new alternative to University of Wisconsin solution, Celsior and histidine-tryptophan-ketoglutarate solution?. World J Gastroenterol. 
2007;13(27):3684-91

6. Straatsburg IH, Abrahamse SL, Song SW, Hartman RJ, Van Gulik TM. Evaluation of rat liver apoptotic and necrotic cell death after Cold Storage Using UW, HTK, and Celsior. Transplantation. 2002;74:458-64.

7. Santos CHM, Gomes OM, Pontes JCDV, Miiji LNO, Bispo MAF. The ischemic preconditioning and postconditioning effect on the intestinal mucosa of rats undergoing mesenteric ischemia/ reperfusion procedure. Acta Cir Bras. 2008;23(1):22-8.

8. Baláz P, Matia I, Jackanin S, Rybárová E, Kron I, Pomfy M, Fronek J, Ryska M. Preservation injury of jejunal grafts and its modulation by custodiol and university of wisconsin perfusion solutions in wistar rats. Eur Surg Res. 2004;36(4):192-7.

9. De Oca J, Hotter G, Sola A, Gonzalez R, Rafecas A, Roselló-Catafau $\mathrm{J}$, Jaurrieta E. Role of nitric oxide in preconditioning for intestinal transplantation. Transplant Proc. 1999;31(6):257-63.

10. Park PO, Haglund U, Bulkley GB, Falt K. The sequence of development of intestinal tissue injury after estrangulation ischemia and reperfusion. Surgery 1990;107:574-80.

11. Uchiyama M, Mihara M. Determination of malonaldehyde precursor in tissues by thiobarbituric acid test. Anal Biochem. 1978;86(1):2718 .

12. Mangus RS, Tector AJ, Fridell JA, Kazimi M, Hollinger E, Vianna RM. Comparison of HTK and Belzer Solution in intestinal and multivisceral transplantation. Transplantation. 2008;86(2):298-02.

13. Montero EFS, Quireze Junior C, D'Oliveira DMR. Bile duct exclusion from selective vascular inflow occlusion in rat liver: role of ischemic preconditioning and $\mathrm{N}$-acetylcysteine on hepatic reperfusion injury. Transplant Proc. 2005;37(1):425-7.

14. Clavien PA, Yadav S, Sindram D. Protective effects of ischemic preconditioning for liver resection performed under inflow occlusion in humans. Ann Surg. 2000;232:155-62.

15. Tesi R, Jaffe B, McBride V, Haque S. Histopathologic changes in human small intestine during storage in Viaspan organ preservation solution. Arch Pathol Lab Med. 1997;121:714-8.

\section{Acknowledgments}

Nair Honda Kawashita, PhD, Assistant Professor of UFMT; Damiana Luiza Pereira de Souza and Gustavo Mitzuo Aiko, graduate students by measurement of MDA content.

\section{Correspondence:}

José de Souza Neves

Rua Desembargador José de Mesquita, 255/202

78005-190 Cuiabá - MT Brasil

Tel: (55 65)9982-1141

jneves@terra.com.br

nevesufmt@gmail.com

Received: February 23, 2011

Review: April 25, 2011

Accepted: May 20, 2011

Conflict of interest: none

Financial source: none

${ }^{1}$ Research performed at the Laboratory of Experimental Surgery, Department of Surgery, Federal University of Mato Grosso, Brazil. Part of Fellow PhD degree thesis. Tutor: Adriano Miziara Gonzalez. Postgraduate Program in Surgical Gastroenterology, Federal University of Sao Paulo (UNIFESP). 